\title{
Effect of maternal nutrient restriction in early gestation on development of the hypothalamic-pituitary-adrenal axis in fetal sheep at $0 \cdot 8-0.9$ of gestation
}

\author{
P Hawkins, C Steyn, H H G McGarrigle, T Saito, T Ozaki, \\ L L Stratford, D E Noakes ${ }^{1}$ and M A Hanson
}

Departments of Obstetrics and Gynaecology and Physiology, University College London, London WC1E 6HX, UK

${ }^{1}$ Department of Farm Animal and Equine Medicine and Surgery, Royal Veterinary College, University of London, AL9 7TA, UK

(Requests for offprints should be addressed to M Hanson, Department of Obstetrics and Gynaecology, 86-96 Chenies Mews, University College London, London WC1E 6HX, UK; Email: m.hanson@ucl.ac.uk)

\begin{abstract}
The fetal hypothalamic-pituitary-adrenal (HPA) axis has numerous key roles in development. Epidemiological data have linked adverse prenatal nutrition with altered organ development and increased incidence of disease in adult life. We studied HPA axis development in resting and stimulated states in late gestation fetal sheep, following $15 \%$ reduction in maternal nutritional intake over the first 70 days of gestation (dGA). Fetuses from control (C) and nutrient-restricted $(\mathrm{R})$ ewes were chronically catheterised and response profiles for ACTH and cortisol were determined at 113-116 and 125-127 dGA after administration of corticotrophin releasing hormone $(\mathrm{CRH})$ and arginine
\end{abstract}

vasopressin (AVP). At 126-128 dGA cortisol profiles were also determined following ACTH administration. Basal $\mathrm{ACTH}$ and cortisol concentrations were not different between $\mathrm{C}$ and $\mathrm{R}$ fetuses. In $\mathrm{R}$ fetuses, $\mathrm{ACTH}$ response to $\mathrm{CRH}+\mathrm{AVP}$ was significantly smaller at 113-116 dGA $(P<0 \cdot 01)$, and cortisol responses were smaller at both 113-116 dGA $(P<0 \cdot 01)$ and 125-127 dGA $(P<0 \cdot 0001)$. Cortisol response to ACTH was also smaller in $\mathrm{R}$ fetuses $(P<0 \cdot 001)$. We conclude that, in late gestation fetal sheep, pituitary and adrenal responsiveness is reduced following modest maternal nutrient restriction in early gestation.

Journal of Endocrinology (1999) 163, 553-561

\section{Introduction}

An adverse intrauterine environment affects development of fetal tissues and organs (Crowe et al. 1995, Phillips et al. 1996). Epidemiological evidence suggests that adult diseases such as coronary heart disease, hypertension and non-insulin-dependent diabetes may originate in utero (see Barker 1998). Therefore, it is thought that developmental programming could be altered by a stimulus or challenge occurring during a sensitive period, to produce long-term changes in physiology and hence determine susceptibility to later disease. Maternal nutrition has been suggested as a factor which could exert programming actions and experimental studies have shown that nutritional changes are capable of producing effects on physiological function in the fetus which have potential consequences for later health (Langley \& Jackson 1994).

The fetal hypothalamic-pituitary-adrenal (HPA) axis has a major role in the response of the fetus to acute episodes of intrauterine stress such as hypoxaemia (Boddy et al. 1974, Akagi \& Challis 1989), haemorrhage (Rose et al. 1978) and hypotension (Rose et al. 1981). In addition, the axis is central to various other processes including organ maturation (Liggins 1994), growth (Fowden 1995), and cardiovascular regulation (Tangalakis et al. 1992). Thus, a functioning HPA axis is critical for normal development of the organism and any perturbations are likely to have consequences for a wide range of systems. Altered HPA function associated with a change in the intrauterine environment has been demonstrated in a number of studies. In humans, altered development indicated by size at birth is linked to HPA axis function, with lower birth weight babies displaying greater rates of urinary glucocorticoid excretion as children (Clark et al. 1996), and elevated basal plasma cortisol concentrations (Phillips et al. 1998) and greater adrenocortical responsiveness to adrenocorticotrophic hormone (ACTH) (Reynolds et al. 1998) as adults. The effect on HPA axis development of direct experimental disruption of the intrauterine environment has also been studied. In the sheep, surgical restriction of placental size produces a decrease in the level of the ACTH precursor, proopiomelanocortin (POMC) mRNA, present in the fetal pituitary (Phillips et al. 1996). The effect of maternal undernutrition on the intrauterine environment and consequently the fetal HPA axis is unknown. 
We tested the hypothesis that a modest nutritional challenge in early gestation would produce an effect on fetal HPA axis function in late gestation. To do this we measured changes in basal plasma concentrations of ACTH and cortisol, and also responses of the pituitary and adrenal glands to imposed challenges, namely exogenous corticotrophin-releasing hormone (CRH) together with arginine vasopressin (AVP), and ACTH. Some of the results have been published in a preliminary form (Hawkins et al. 1997a).

\section{Materials and Methods}

\section{Dietary manipulation}

Prior to conception Welsh Mountain ewes of uniform age, weight and body condition score were randomly assigned to either the control (C) or the nutrient-restricted (R) group. A hierarchical feeding system exists within groups of sheep; accordingly in order to permit specific regulation of individual nutritional intake the animals used in this study were housed in individual pens. The floors of all pens were covered with wood shavings, and the animals were fed a complete pelleted diet which was regulated depending on the protocol. Animals were allowed free access to water. The diet consisted of barley, wheat, cooked cereal meal, micronized full fat soya, grass meal, molasses, chopped straw, calcium carbonate, dicalcium phosphate, salt, and a sheep vitamin/mineral supplement. It provided $10 \cdot 81 \mathrm{MJ} / \mathrm{kg}$ metabolisable energy, $149 \cdot 8 \mathrm{~g} /$ $\mathrm{kg}$ crude protein and contained $88.4 \%$ dry matter. Rations were allocated based upon recommendations made by an advisory manual prepared by the AFRC Technical Committee on responses to nutrients (AFRC 1993). The diet rations were adjusted according to the stage of gestation. Nutrient intake was regulated by reducing the amount of the recommended daily ration. All components of the diet were reduced by the same degree.

Control animals were fed $100 \%$ of their recommended nutritional requirements for the whole of gestation. Nutrient-restricted animals received $85 \%$ of their recommended nutrient requirements from the time of conception until day 70 of gestation, and $100 \%$ of their requirements thereafter. Thus $\mathrm{R}$ animals received $15 \%$ less compared with $\mathrm{C}$ for the first 70 days of gestation only. Maternal body weight and condition score (see Russel 1991) were measured on a weekly basis.

\section{Surgical procedures}

All surgical procedures were approved by the Home Office and were conducted in accordance with the Animals (Scientific Procedures) Act 1986. Aseptic surgery was performed on fourteen singleton-bearing ewes at 107-109 days gestation (dGA) (term is 147 days) under general anaesthesia (1 $\mathrm{g}$ thiopentone i.v. for induction; $2 \%$ halothane in oxygen for maintenance). The uterus was exposed through an incision in the midline of the lower abdominal wall, and the fetus partially exteriorised. Catheters filled with heparinised saline (i.d. $=1.0 \mathrm{~mm}$; o.d. $=2.0 \mathrm{~mm}$, translucent vinyl tubing, Portex Ltd) were placed in a fetal carotid artery, jugular vein and the amniotic cavity. A catheter was also placed in a maternal pedal vein. The fetal catheters were exteriorised through the maternal flank. Following surgery, antibiotics were administered to the ewe (4 $\mathrm{ml}$ Streptopen i.m.; Pitman and Moore, Crewe, Cheshire, UK) and into the amniotic cavity (600 mg Crystapen; Britannia Pharmaceuticals, Redhill, Surrey, UK, and $80 \mathrm{mg}$ Gentamicin; DBL, Tachbrook Park, Warwick, UK). At least four days postoperative recovery were allowed prior to commencing experiments. During this time antibiotics were administered daily to the ewe (300 mg Crystapen i.v.), fetus (150 mg Crystapen i.v.) and into the amniotic cavity (150 mg Crystapen i.v.). Gentamicin was administered on days 1 and 2 only to the ewe ( $40 \mathrm{mg}$ i.v.) and into the amniotic cavity $(40 \mathrm{mg})$. Catheters were maintained patent by continuous infusion of heparinised saline $\left(50 \mathrm{IU} \mathrm{ml}^{-1}\right.$ at $\left.0 \cdot 125 \mathrm{ml} \mathrm{h}^{-1}\right)$. Fetal arterial blood was collected daily for $\mathrm{pH}$, blood gas, haematocrit (Hct), haemoglobin $(\mathrm{Hb})$, and blood glucose and lactate analysis.

\section{Experimental procedures}

Fetuses were studied over a fourteen-day period between 113-116 and 126-128 dGA. Seven arterial blood samples $(1 \mathrm{ml})$ were taken from each fetus during the course of the study on the morning of every second day for determination of basal plasma ACTH and cortisol levels. At both 113-116 and 125-127 dGA fetuses received an intravenous bolus of ovine CRH (1 $\mu$ g; Sigma Chemical Co., Poole, Dorset, UK) plus AVP (200 ng; Sigma Chemical Co.). Both peptides were dissolved in $0.1 \%$ bovine serum albumin in sterile saline and administered together in a volume of $1 \mathrm{ml}$. Fetal arterial blood samples $(0.6 \mathrm{ml})$ were taken for ACTH and cortisol analysis at 30 and $0 \mathrm{~min}$ before, and 5, 10, 15, 30, 60, 120, and $180 \mathrm{~min}$ after the injection. Additional samples of fetal arterial blood $(0.5 \mathrm{ml})$ were collected $30 \mathrm{~min}$ before, and 15, 45, and $90 \mathrm{~min}$ after the injection for blood gas analysis. On the day following the second CRH+AVP challenge (i.e. 126-128 dGA), fetuses received an intravenous bolus of $300 \mathrm{ng}$ ACTH (1-24; Sigma Chemical Co.). ACTH was dissolved in $0 \cdot 1 \%$ bovine serum albumin in sterile saline and administered in a volume of $1 \mathrm{ml}$. Fetal arterial blood samples $(0.6 \mathrm{ml})$ were taken for ACTH and cortisol analysis at 30 and $0 \mathrm{~min}$ before, and 5, 10, 15, 30, 60, and $120 \mathrm{~min}$ after the injection. Additional samples of fetal arterial blood $(0.5 \mathrm{ml})$ were collected $30 \mathrm{~min}$ before and 15,45 , and $90 \mathrm{~min}$ after the injection for blood gas analysis. 
At the end of the study period at 127-129 dGA, ewes were killed by an overdose of pentobarbitone $(40 \mathrm{ml}$ Euthatal i.v.; Rhône Mérieux, Harlow, Essex, UK). Maternal and fetal body weights, fetal heart, lung, liver, individual kidney, and individual adrenal weights, crownrump length, abdominal circumference, and femur length were recorded. The fetal body and organs were examined for any macroscopic abnormalities.

\section{Collection of plasma for hormone analysis}

Blood samples were collected from animals using aseptic techniques and transferred into EDTA polypropylene collection tubes kept on ice. These were centrifuged at $0{ }^{\circ} \mathrm{C}$ at $2000 \mathrm{~g}$ for $10 \mathrm{~min}$. Plasma was removed, aliquoted and then stored at $-40{ }^{\circ} \mathrm{C}$ until assayed.

\section{Hormone assays}

ACTH assay Plasma ACTH levels were measured using a double-antibody ${ }^{125} \mathrm{I}$ radioimmunoassay (RIA). All reagents were purchased in kit form from Diagnostics Products Ltd (Abingdon, Oxon, UK). The kit contained rabbit anti-human ACTH antiserum, a set of ACTH standards calibrated against the Medical Research Council's reference preparation (MRC 74/555 human ACTH(1-39)), ${ }^{125}$ I-ACTH and a second antibodyprecipitating mixture of goat anti-rabbit g-globulin antiserum and dilute polyethylene glycol (PEG) in saline. Duplicate $100 \mu \mathrm{l}$ plasma samples were incubated with $100 \mu \mathrm{l}$ anti-ACTH antiserum and $100 \mu \mathrm{l}^{125} \mathrm{I}-\mathrm{ACTH}$ for $24 \mathrm{~h}$. The bound and free hormone fractions were separated by mixing with $1.0 \mathrm{ml}$ of the second antibody/ PEG solution. Following centrifugation the precipitate was retained for counting.

The interassay coefficients of variation for three controls (26, 94 and $296 \mathrm{pg} \mathrm{ml}^{-1} \mathrm{ACTH}$ ) in three assay batches were $12 \cdot 9,8 \cdot 2$, and $6 \cdot 7 \%$ respectively. The sensitivity of the assay was $8 \mathrm{pg} \mathrm{ml}^{-1}$.

The anti-ACTH antiserum showed $0 \cdot 2 \%$ crossreactivity against $\alpha$-melanocyte-stimulating hormone $(\alpha-$ $\mathrm{MSH}$ ) and no detectable cross-reactivity against $\beta$-endorphin (human), $\left[\mathrm{met}^{5}\right]$ enkephalin, $\left[\mathrm{eu}{ }^{5}\right]$ enkephalin, neurotensin, substance-P and somatostatin.

Cortisol assay Plasma cortisol concentrations were also measured by RIA using tritium-labelled cortisol as tracer, as described previously (Giussani et al. 1994). Briefly, duplicate $20 \mu \mathrm{l}$ plasma samples were mixed with an equal volume of sodium carbonate solution (1.7 M, pH 10.5) and extracted with $2.5 \mathrm{ml}$ diethyl ether. After freezing, the ether was decanted and evaporated, and the residue reconstituted in $500 \mu \mathrm{l}$ phosphate-buffered saline (PBS; $\mathrm{pH} 7 \cdot 4$ ). Aliquots of varying volumes (depending on expected results following pilot studies) were removed, made up to $400 \mu \mathrm{l}$ with PBS and incubated with 16000 d.p.m. $\quad\left[1,2,6,7-{ }^{3} \mathrm{H}\right]$ cortisol (Amersham International, Aylesbury, Bucks, UK) and $100 \mu \mathrm{l}$ rabbit anticortisol antiserum (Biochemical Services, Cardiff, UK). Bound and free steroids were separated using dextrancoated charcoal and after centrifugation a $500 \mu \mathrm{l}$ aliquot was removed for measuring radioactive content.

Recoveries averaged 94\%. Interassay coefficients of variation for three control plasma pools $(16 \cdot 8,62 \cdot 4$ and $123.7 \mathrm{nmol}^{-1}$ cortisol) in twelve assay batches were 11.2 , $7 \cdot 4$ and $6 \cdot 8 \%$ respectively. The sensitivity of the assay was $30 \mathrm{fmol} \mathrm{ml}{ }^{-1}$.

The ACTH and cortisol assays were previously validated for use in fetal sheep (see Giussani et al. 1994).

\section{Blood gas analysis}

Blood gases, $\mathrm{pH}$ and Hct were measured on a blood gas analyser (BGE, Instrumentation Laboratory, Warrington, Cheshire, UK, values corrected to $39 \cdot 5^{\circ} \mathrm{C}$ ). A haemoximeter was used for measurement of $\mathrm{Hb}$ (CO-oximeter 482: Instrumentation Laboratory) and glucose and lactate were measured by a glucose-lactate analyser (YSI, 2300 STAT PLUS).

\section{Data analysis}

All values are presented as means \pm S.E.M. In all the statistical tests significance was accepted when $P<0 \cdot 05$. When multiple comparisons were made, $P$ values were corrected using the Bonferroni method. After analysis of cortisol data we found that values for one fetus were well outside the physiological range expected for that gestational age. At post mortem it was found that the fetus also had abnormal brain development. Endocrine data collected from this fetus were therefore excluded from the analysis.

Maternal data Data for maternal body weight and condition score were expressed as a percentage change from baseline (mean of 3 previous measurements up to and including conception). The percentage change from baseline was then calculated for all subsequent weekly measurements, until 119 dGA. Data are not shown for the period after 119 dGA as after this point the number of animals in each group decreases because they were used for different studies. Maternal data were compared using summary measures analysis (Matthews et al. 1990). The experimental period was divided into three time periods: 0-70 dGA, 70-119 dGA and 0-119 dGA. Within these time periods, weekly measurements of the percentage change were averaged to produce a summary measure. Summary measures were then compared between $\mathrm{C}$ and $\mathrm{R}$ animals, using Student's unpaired $t$-test to determine significance. 
Fetal data Data for fetal body proportions, body weight and organ weights were compared between $\mathrm{C}$ and $\mathrm{R}$ fetuses using Student's unpaired $t$-test. Daily measurements of basal blood gas data were averaged to give a single value for the whole of the two-week study period. Values were then compared between $\mathrm{C}$ and $\mathrm{R}$ fetuses using Student's unpaired $t$-test. During the CRH+AVP or ACTH administration experiments, differences for blood gas parameters between $\mathrm{C}$ and $\mathrm{R}$ fetuses were determined by comparing each data point using Student's unpaired $t$-test. The changes in blood gas parameters during these experiments within each group were analysed by comparing the value at $-30 \mathrm{~min}$ with the subsequent values obtained. Significance was determined by Student's paired $t$-test.

ACTH and cortisol data were transformed logarithmically before analysis to remove heterogeneity of variance. These data were compared between $\mathrm{C}$ and $\mathrm{R}$ fetuses using two-way analysis of variance comparing the effect of group ( $C$ vs $\mathrm{R}$ ), time and the interaction between group and time. Basal ACTH and cortisol data were divided into seven groups according to gestational age, with the first group designated 114-115 dGA, and the final group 126-127 dGA. Data that were outside these groupings were not used in the analysis. To determine if values changed over the two-week period within each group, samples at 114-115 dGA were compared with 126-127 dGA by Student's paired $t$-test. To determine if significant changes in ACTH and cortisol occurred within each group during the $\mathrm{CRH}+\mathrm{AVP}$ or ACTH administration experiments, the value at 0 min was compared with the peak value in the postinjection period, and with the value at $180 \mathrm{~min}$ for the CRH+AVP experiments, or with the value at $120 \mathrm{~min}$ for the ACTH administration experiment. Significance was determined using Student's paired $t$-test.

\section{Results}

\section{Maternal body weight and condition score}

The change from baseline of maternal body weight was significantly different between $\mathrm{C}(n=36)$ and $\mathrm{R}(n=39)$ ewes at $0-70$ dGA $(P<0 \cdot 05)$ (Fig. 1). The change from baseline of maternal condition score was significantly different between $\mathrm{C}$ and $\mathrm{R}$ ewes over the gestational periods 0-70 dGA $(P<0 \cdot 005), 70-119 \mathrm{dGA}(P<0 \cdot 05)$, and 0-119 dGA $(P<0 \cdot 0001)$ (Fig. 1).

\section{Fetal growth and organ weights}

There were no significant differences between the groups for any of the measurements of fetal growth or fetal organ weights (Table 1). There were two female fetuses in each group.
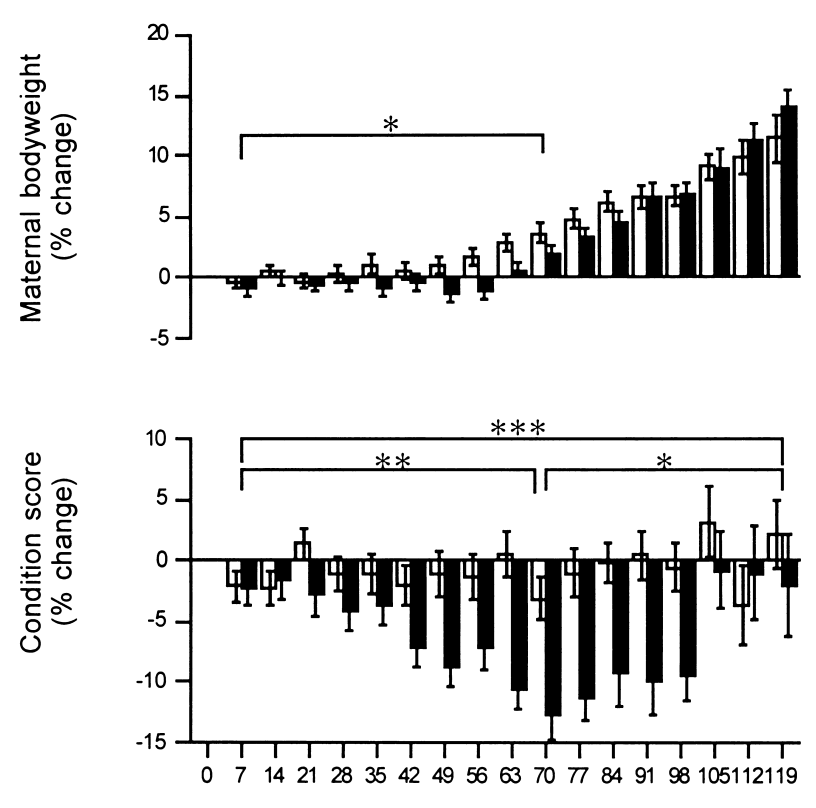

\section{GESTATIONAL AGE (DAYS)}

Figure 1 The percentage change from baseline in maternal body weight and condition score of C (open bars) and R (solid bars) ewes during 0-119 days of gestation. Values are presented as means \pm S.E.M. ${ }^{*} P<0 \cdot 05,{ }^{*} P<0 \cdot 005,{ }^{* * *} P<0 \cdot 0001 \mathrm{C}$ compared with $\mathrm{R}$ (unpaired $t$-test).

\section{Fetal blood gases}

Data for basal blood gases are shown in Table 2. Data for the blood gas changes during administration of CRH+AVP at 113-116 dGA are also shown, to illustrate the response that occurs. There were no differences

Table 1 Data for fetal body weight, body proportions and organ weights in $\mathrm{C}(n=7)$ and $\mathrm{R}(n=7)$ fetuses. Data for organ weights are shown as absolute values and as a percentage of body weight (BW). Values are presented as means \pm S.E.M.

Fetal body weight $(\mathrm{kg})$ Crown-rump length $(\mathrm{cm})$ Abdominal circumference $(\mathrm{cm})$ Femur length $(\mathrm{cm})$

Heart (g)

Lung (g)

Liver (g)

Kidneys (g)

Adrenals $(\mathrm{g})$

Heart $(\% \mathrm{BW})$

Lung (\%BW)

Liver (\%BW)

Kidneys (\%BW)

Adrenals (\%BW)

\begin{tabular}{|c|c|}
\hline & $\mathbf{R}$ \\
\hline $3 \cdot 15 \pm 0 \cdot 17$ & $3 \cdot 06 \pm 0 \cdot 15$ \\
\hline $46 \cdot 04 \pm 14 \cdot 67$ & $46 \cdot 09 \pm 8 \cdot 28$ \\
\hline $32.90 \pm 7.95$ & $32 \cdot 89 \pm 6 \cdot 72$ \\
\hline $9 \cdot 31 \pm 3 \cdot 17$ & $9 \cdot 36 \pm 3 \cdot 73$ \\
\hline $23.46 \pm 1 \cdot 50$ & $22 \cdot 87 \pm 1 \cdot 34$ \\
\hline $75 \cdot 27 \pm 7 \cdot 27$ & $69 \cdot 57 \pm 3 \cdot 60$ \\
\hline $104 \cdot 50 \pm 7 \cdot 68$ & $114 \cdot 03 \pm 9 \cdot 10$ \\
\hline $22 \cdot 04 \pm 2 \cdot 27$ & $20 \cdot 14 \pm 1 \cdot 41$ \\
\hline $0.93 \pm 0.50$ & $0.39 \pm 0.02$ \\
\hline $0.74 \pm 0.03$ & $0 \cdot 75 \pm 0.05$ \\
\hline $2 \cdot 42 \pm 0 \cdot 27$ & $2 \cdot 29 \pm 0 \cdot 14$ \\
\hline $3 \cdot 32 \pm 0 \cdot 17$ & $3 \cdot 77 \pm 0.37$ \\
\hline $0 \cdot 70 \pm 0.07$ & $0.66 \pm 0.04$ \\
\hline $0.03 \pm 0.02$ & $0 \cdot 01 \pm 0 \cdot 00$ \\
\hline
\end{tabular}

There were no significant differences between $C$ and $R$ fetuses. 
Table 2 Data for fetal blood gases under basal conditions, and during the CRH+AVP experiment at $113-116 \mathrm{dGA}$ in $\mathrm{C}(n=7)$ and $\mathrm{R}$ $(n=7)$ fetuses. Basal values are the mean of daily measurements taken over the two-week study period. Values are presented as means \pm S.E.M.

\begin{tabular}{|c|c|c|c|c|c|}
\hline & \multirow[b]{2}{*}{ Basal } & \multicolumn{4}{|c|}{ CRH+AVP (113-116 dGA) } \\
\hline & & $-30 \min$ & $15 \min$ & $45 \min$ & $90 \min$ \\
\hline \multicolumn{6}{|l|}{$\mathrm{pH}$} \\
\hline $\mathrm{R}$ & $7 \cdot 34 \pm 0 \cdot 01$ & $7 \cdot 35 \pm 0 \cdot 01$ & $7 \cdot 33 \pm 0 \cdot 01^{* * *}$ & $7 \cdot 33 \pm 0 \cdot 01^{* *}$ & $7 \cdot 34 \pm 0 \cdot 00$ \\
\hline \multicolumn{6}{|c|}{$\mathrm{PaCO}_{2}(\mathrm{mmHg})$} \\
\hline C & $45 \cdot 58 \pm 1 \cdot 26$ & $45 \cdot 00 \pm 2 \cdot 13$ & $43 \cdot 53 \pm 1 \cdot 53$ & $45 \cdot 20 \pm 2 \cdot 19$ & $43 \cdot 65 \pm 1 \cdot 57$ \\
\hline C & $25 \cdot 19 \pm 0 \cdot 90$ & $25 \cdot 83 \pm 0 \cdot 79$ & $28 \cdot 67 \pm 1 \cdot 20^{*}$ & $24 \cdot 83 \pm 1 \cdot 35$ & $26 \cdot 17 \pm 0 \cdot 60$ \\
\hline $\mathrm{R}$ & $24 \cdot 40 \pm 0 \cdot 71$ & $25 \cdot 00 \pm 0 \cdot 98$ & $27 \cdot 71 \pm 1 \cdot 02^{\star \star \star}$ & $24 \cdot 86 \pm 0 \cdot 60$ & $25 \cdot 43 \pm 0 \cdot 75$ \\
\hline \multicolumn{6}{|c|}{ Hct (\%) } \\
\hline C & $26 \cdot 16 \pm 0 \cdot 77$ & $22 \cdot 33 \pm 0 \cdot 67$ & $23 \cdot 00 \pm 0 \cdot 52$ & $22 \cdot 83 \pm 0 \cdot 40$ & $21 \cdot 50 \pm 0.96$ \\
\hline $\mathrm{R}$ & $26 \cdot 06 \pm 1 \cdot 02$ & $23 \cdot 00 \pm 0 \cdot 87$ & $24 \cdot 00 \pm 0 \cdot 76^{*}$ & $22 \cdot 43 \pm 0.65$ & $23 \cdot 14 \pm 0 \cdot 51$ \\
\hline \multicolumn{6}{|c|}{$\mathrm{Hb}(\mathrm{g} / \mathrm{dl})$} \\
\hline \multicolumn{6}{|c|}{ Glucose (nmol/l) } \\
\hline C & $0 \cdot 81 \pm 0 \cdot 06$ & $0 \cdot 82 \pm 0 \cdot 14$ & $1 \cdot 01 \pm 0 \cdot 18^{*}$ & $0.91 \pm 0.17$ & $0.97 \pm 0.15^{* *}$ \\
\hline $\mathrm{R}$ & $0 \cdot 79 \pm 0 \cdot 03$ & $0.80 \pm 0.03$ & $0.91 \pm 0.07^{*}$ & $0 \cdot 81 \pm 0 \cdot 05$ & $0 \cdot 89 \pm 0.06^{*}$ \\
\hline
\end{tabular}

${ }^{*} P<0 \cdot 05,{ }^{* *} P<0 \cdot 01,{ }^{* * *} P<0 \cdot 001$ (paired $t$-test) compared with value at $-30 \mathrm{~min}$.

between $\mathrm{C}$ and $\mathrm{R}$ fetuses for any of the blood gas parameters under basal conditions. There were no differences between $\mathrm{C}$ and $\mathrm{R}$ fetuses in the response to CRH+AVP administration at 113-116 dGA or 125-127 dGA, or to administration of ACTH. As illustrated in Table 2, administration of CRH+AVP caused a significant decrease in $\mathrm{pH}$, and significant increases in $\mathrm{PaO}_{2}$, lactate and glucose when compared with $-30 \mathrm{~min}$ in both $\mathrm{C}$ and $\mathrm{R}$ fetuses. Similar changes also occurred in response to $\mathrm{CRH}+\mathrm{AVP}$ at 125-127 dGA. Administration of ACTH did not cause any significant changes in fetal blood gas status.

\section{Basal ACTH and cortisol}

Basal plasma concentrations of ACTH were very low throughout the course of the study; indeed many samples were below the sensitivity of the assay. Thus, there were no detectable differences between the groups. Basal cortisol concentrations did not differ between $\mathrm{C}$ and $\mathrm{R}$ fetuses (Fig. 2). At 114-115 dGA plasma cortisol concentrations were $7 \cdot 12 \pm 0.36 \mathrm{nmol} \mathrm{l}^{-1}$ in $\mathrm{C}$ fetuses and $7 \cdot 20 \pm$ $1.31 \mathrm{nmol}^{-1}$ in $\mathrm{R}$ fetuses. At 126-127 dGA, cortisol concentrations were $16 \cdot 12 \pm 4 \cdot 83 \mathrm{nmol} \mathrm{l}^{-1}$ in $\mathrm{C}$ fetuses and $12.02 \pm 3.75 \mathrm{nmol} \mathrm{l}^{-1}$ in $\mathrm{R}$ fetuses. Cortisol concentrations were significantly greater in $\mathrm{C}$ fetuses at 126-127 dGA compared with 114-115 dGA $(P<0 \cdot 05)$, but not in $\mathrm{R}$ fetuses.

\section{Responses to $C R H+A V P$ challenge}

At 113-116 dGA, a significant effect of group was found for the ACTH $(P<0 \cdot 01)$ and cortisol $(P<0 \cdot 01)$ responses to $\mathrm{CRH}+\mathrm{AVP}$, which were smaller in $\mathrm{R}$ fetuses

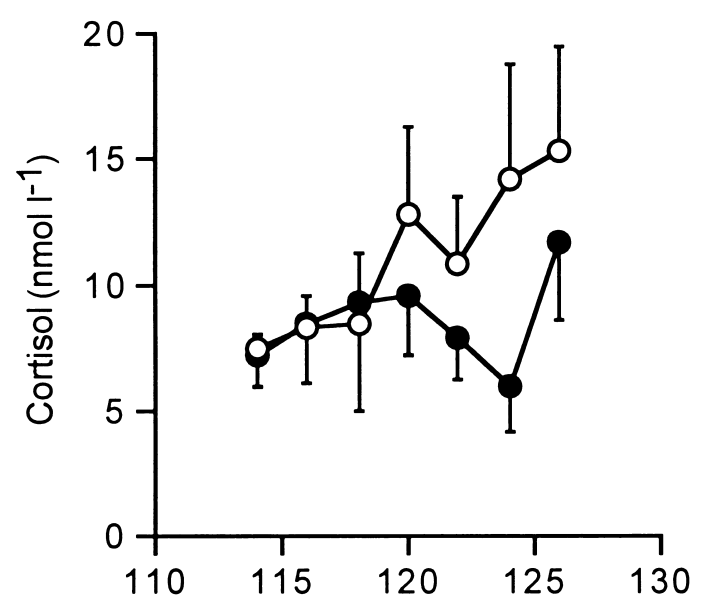

\section{Gestational Age (days)}

Figure 2 Basal plasma cortisol concentrations in $\mathrm{C}(\bigcirc, n=7)$ and $R(\bullet, n=6)$ fetuses between 114-127 days of gestation. Values are presented as means \pm S.E.M. There was no significant difference between $\mathrm{C}$ and $\mathrm{R}$ fetuses. 

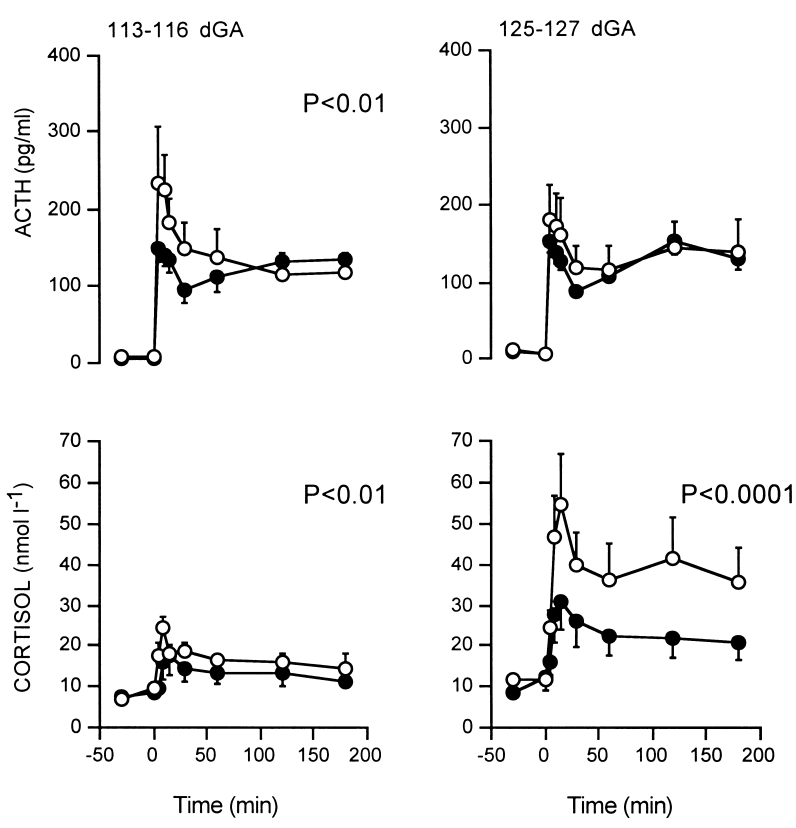

Figure 3 Response profiles for plasma ACTH (upper panels) and cortisol (lower panels) 30 min before and 180 min after injection of $1 \mu \mathrm{g}$ CRH plus $200 \mathrm{ng}$ AVP in $\mathrm{C}(\bigcirc, n=7)$ and $\mathrm{R}(\bullet, n=6)$ fetuses. The panels on the left show the response at 113-116 dGA, those on the right show the response at 125-127 dGA. Values are presented as means \pm S.E.M. At 113-116 dGA, ACTH $(P<0 \cdot 01)$ and cortisol $(P<0 \cdot 01)$ responses were smaller in $\mathrm{R}$ fetuses compared with $C$ fetuses. At 125-127 dGA, the cortisol response $(P<0.0001)$ was smaller in $\mathrm{R}$ fetuses compared with $\mathrm{C}$ fetuses.

compared with C fetuses (Fig. 3). At 125-127 dGA, a significant effect of group was found for the cortisol response $(P<0 \cdot 0001)$, which was smaller in $\mathrm{R}$ fetuses compared with $\mathrm{C}$ fetuses. The ACTH response at 125 127 dGA was not different between $\mathrm{C}$ and $\mathrm{R}$ fetuses (Fig. 3).

At 113-116 dGA, plasma ACTH concentrations were at their maximum at $5 \mathrm{~min}$ in both groups, with values reaching $272.00 \pm 72.62 \mathrm{pg} / \mathrm{ml}$ in $\mathrm{C}$ fetuses and $144.33 \pm$ $19.86 \mathrm{pg} / \mathrm{ml}$ in $\mathrm{R}$ fetuses. When the value at $5 \mathrm{~min}$ was compared with $0 \mathrm{~min}$ (preinjection) it was found that the increase was significant in both $\mathrm{C}(P<0 \cdot 001)$ and $\mathrm{R}$ $(P<0 \cdot 0001)$ fetuses. ACTH concentrations remained elevated and were significantly greater at $180 \mathrm{~min}$ compared with 0 min in both $\mathrm{C}(P<0 \cdot 001)$ and $\mathrm{R}(P<0 \cdot 0001)$ fetuses. At 113-116 dGA, the maximum cortisol concentration in C fetuses was $24.60 \pm 2.78 \mathrm{nmol} \mathrm{l}^{-1}$, and occurred at $10 \mathrm{~min}$. This value was significantly greater than at $0 \mathrm{~min}(P<0 \cdot 05)$. The maximum cortisol concentration in $\mathrm{R}$ fetuses was $17 \cdot 85 \pm 4.97 \mathrm{nmol} \mathrm{l}^{-1}$, and occurred at $15 \mathrm{~min}$. This value was not significantly different from $0 \mathrm{~min}$. Cortisol concentrations did not remain elevated, and were not significantly different at $180 \mathrm{~min}$ compared with $0 \mathrm{~min}$ in either group of fetuses.

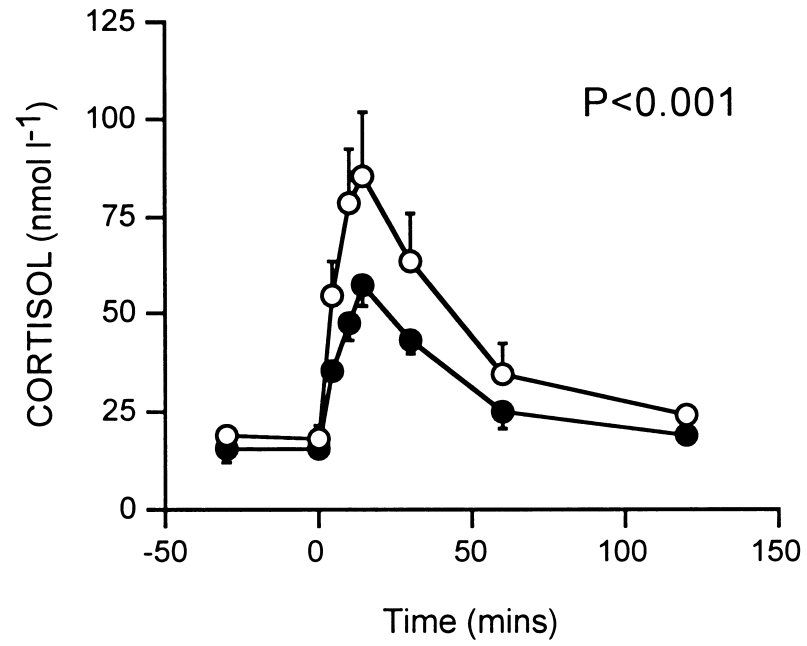

Figure 4 Response profiles for plasma cortisol 30 min before and 120 min after injection of $300 \mathrm{ng} \mathrm{ACTH}$ at 126-128 dGA in C $(\bigcirc, n=7)$ and $R(\bullet, n=6)$ fetuses. Values are presented as means \pm S.E.M. The cortisol response profile was significantly smaller in $\mathrm{R}$ fetuses $(P<0 \cdot 001)$.

At 125-127 dGA, ACTH concentrations were maximum at $5 \mathrm{~min}$ in both groups, with values reaching $181 \cdot 00 \pm 44 \cdot 14 \mathrm{pg} / \mathrm{ml}$ in $\mathrm{C}$ fetuses and $148 \cdot 75 \pm$ $16.31 \mathrm{pg} / \mathrm{ml}$ in $\mathrm{R}$ fetuses. When the 5 -min value was compared with that at $0 \mathrm{~min}$ it was found that the increase was significant in both $\mathrm{C}(P<0 \cdot 0001)$ and $\mathrm{R}(P<0 \cdot 0001)$ fetuses. ACTH concentrations were still elevated at the end of the sampling period, and values at $180 \mathrm{~min}$ were significantly greater compared with $0 \mathrm{~min}$ in both $\mathrm{C}$ $(P<0 \cdot 0001)$ and $\mathrm{R}(P<0 \cdot 0001)$ fetuses. At $125-127 \mathrm{dGA}$, maximum cortisol concentrations occurred at $15 \mathrm{~min}$ in both groups, and were $54 \cdot 86 \pm 11 \cdot 90 \mathrm{nmol} \mathrm{l}^{-1}$ in C fetuses and $30 \cdot 77 \pm 7 \cdot 04 \mathrm{nmol}^{-1}$ in $\mathrm{R}$ fetuses. These values were significantly greater compared with $0 \mathrm{~min}$ in $\mathrm{C}(P<0 \cdot 01)$ and $\mathrm{R} \quad(P<0 \cdot 001)$ fetuses. Cortisol concentrations remained elevated for the duration of the experiment, and were greater at $180 \mathrm{~min}$ compared with $0 \mathrm{~min}$ in both $\mathrm{C}$ $(P<0 \cdot 05)$ and $\mathrm{R}(P<0 \cdot 05)$ fetuses.

\section{Response to ACTH challenge}

A significant effect of group was found for the cortisol response to ACTH, which was smaller in $\mathrm{R}$ fetuses compared with $\mathrm{C}$ fetuses $(P<0 \cdot 001)$ (Fig. 4).

$\mathrm{ACTH}$ concentrations were maximum at $5 \mathrm{~min}$, and were $14.43 \pm 1.36 \mathrm{pg} / \mathrm{ml}$ in $\mathrm{C}$ fetuses and $16.05 \pm$ $2.58 \mathrm{pg} / \mathrm{ml}$ in $\mathrm{R}$ fetuses. When these values were compared with those at $0 \mathrm{~min}$ it was found that these increases were significant in both $\mathrm{C}(P<0 \cdot 0001)$ and $\mathrm{R}(P<0 \cdot 001)$ fetuses. ACTH concentrations did not remain elevated, and were not significantly different at 120 min compared with $0 \mathrm{~min}$ in either group of fetuses. The ACTH response profile was not different between $\mathrm{C}$ and $\mathrm{R}$ fetuses. 
Cortisol concentrations were maximum at $15 \mathrm{~min}$, and were $85 \cdot 49 \pm 16 \cdot 14 \mathrm{nmol} \mathrm{l}^{-1}$ in $\mathrm{C}$ fetuses and $57 \cdot 43 \pm$ $5.77 \mathrm{nmol} \mathrm{l}^{-1}$ in $\mathrm{R}$ fetuses. When these values were compared with those at $0 \mathrm{~min}$ it was found that the increase was significant in both $\mathrm{C}(P<0.0001)$ and $\mathrm{R}$ $(P<0 \cdot 001)$ fetuses. Cortisol concentrations remained elevated in $\mathrm{C}$ fetuses only, and were significantly greater at 120 min compared with 0 min $(P<0 \cdot 05)$.

\section{Discussion}

This study shows that modest restriction of maternal nutrition in early gestation produces depressed HPA axis function in the fetus in late gestation, characterised by reduced pituitary and adrenal responsiveness, even in the absence of any adverse effects on fetal growth.

Fetal HPA axis function was assessed by exogenous administration of CRH+AVP and ACTH. These challenges elicit $\mathrm{ACTH}$ and cortisol responses which are readily quantifiable and reproducible (Norman \& Challis 1987, Brooks \& White 1990, Harvey et al. 1993). Previous studies (Norman \& Challis 1987) and our own preliminary data have shown that one microgram $\mathrm{CRH}$ produces a submaximal ACTH response. In the present study, R fetuses displayed significantly smaller plasma ACTH responses following $\mathrm{CRH}+\mathrm{AVP}$ stimulation compared with C fetuses at 113-116 dGA. Circulating ACTH acts at the adrenal cortex, promoting steroidogenesis and increased secretion of cortisol. Due to the relatively unresponsive nature of the fetal adrenal cortex to ACTH at 113-116 dGA (Wintour et al. 1975), CRH+AVP administration stimulated only small changes in plasma cortisol concentration. However, R fetuses did not show a significant increase in cortisol, and the overall response was significantly smaller compared with C fetuses. At 125-127 dGA CRH+AVP administration produced substantial activation of the adrenal gland and plasma cortisol concentration increased significantly in both groups but, as at 113-116 dGA, the response was significantly smaller in $\mathrm{R}$ compared with $\mathrm{C}$ fetuses.

The plasma cortisol response to direct adrenocortical stimulation by exogenous ACTH was also smaller in $\mathrm{R}$ fetuses. These data confirm the observations made following the CRH+AVP test demonstrating that, as at the pituitary, the response of the adrenal gland was blunted in $\mathrm{R}$ fetuses. Moreover, it is clear that this effect was present at both gestational age ranges studied.

The smaller plasma ACTH and cortisol responses in R fetuses suggest that stimulated secretion of ACTH and cortisol was reduced in this group. Alternatively, alterations in the rates of clearance of these endocrine agents could have contributed to the reduced responses. Administration of $\mathrm{CRH}+\mathrm{AVP}$ also produces effects on fetal blood gas function, and on the cardiovascular system, particularly through the actions of AVP (Iwamoto et al. 1979), which may have consequences for HPA axis function. However, we have shown that the cardiovascular (unpublished observations) and blood gas changes produced by $\mathrm{CRH}+\mathrm{AVP}$ administration do not differ between $\mathrm{C}$ and $\mathrm{R}$ fetuses, indicating that the altered endocrine responses result from the direct effects of $\mathrm{CRH}+\mathrm{AVP}$ on the HPA axis.

At the pituitary, reduced levels of POMC, or alterations in post-translational processing and/or ACTH secretory mechanisms could have reduced responsiveness and resulted in the smaller CRH+AVP-stimulated ACTH response in $\mathrm{R}$ fetuses. Pituitary POMC levels may be downregulated by an increase in the efficacy of glucocorticoid-mediated negative feedback mechanisms. This effect could be mediated by exposure to elevated plasma glucocorticoid concentrations (Jeffray et al. 1998), or by an increase in pituitary glucocorticoid receptor number. Pituitary responsiveness could also be reduced by downregulation of $\mathrm{CRH}$ receptor numbers, and experiments have shown that this type of effect is associated with an attenuation of ACTH secretion (Lu et al. 1994). We are currently performing studies to investigate these possibilities.

Differences in the plasma cortisol responses following exogenous stimulation could have been a consequence of differences in size of the adrenal gland. The increase in adrenal size and in the numbers of steroidogenic cells at the adrenal cortex during late gestation (Boshier \& Holloway 1989) is associated with elevation of adrenocortical responsiveness to ACTH (Wintour et al. 1975, Glickman \& Challis 1980, Rose et al. 1982). In the present study, although adrenal weight appeared to be greater in $\mathrm{C}$ fetuses compared with $\mathrm{R}$ fetuses, the value for $\mathrm{C}$ fetuses did not reflect the distribution within the group accurately. The large arithmetic mean value and S.E.M. for the $\mathrm{C}$ group was produced by a single outlying value. When this value was excluded, the mean adrenal weight of $\mathrm{C}$ fetuses was $0.43 \pm 0.05 \mathrm{~g}$. Thus, the adrenal weights of the groups were comparable with other published investigations (Boshier et al. 1980, Lye et al. 1983), and did not differ between $\mathrm{C}$ and $\mathrm{R}$ fetuses, indicating that the smaller responses were not a result of reduced adrenal growth in the $\mathrm{R}$ group.

Changes in fetal adrenocortical responsiveness during late gestation are also determined by alterations in expression of the enzymes involved in the steroid biosynthetic pathway, including cholesterol side-chain cleavage enzyme $\left(\mathrm{P}^{4} 50_{\mathrm{scc}}\right)$ and $17 \alpha$-hydroxylase (Tangalakis et al. 1989). The possibility that levels of these enzymes were reduced in $\mathrm{R}$ fetuses is currently under investigation. In addition, the smaller cortisol responses in $\mathrm{R}$ fetuses could have been produced by reduced delivery of circulating ACTH to its site of action at the adrenal cortex, for example by a reduction of adrenocortical blood flow. However, our data do not support this idea, as a chronic decrease in blood flow to the adrenal gland would also 
reduce the supply of nutrients and/or oxygen, thus decreasing adrenal growth, and as discussed, this effect did not occur in the present study.

Changes in activity of the fetal HPA axis could have a number of important effects. The increase in activity of the axis and rise in plasma ACTH and cortisol concentration during late gestation is critical for maturation of many different organ systems including the lung, and in the overall preparation of the fetus for extrauterine life (Liggins 1994, Fowden 1995). Insufficient release of pituitary ACTH combined with reduced adrenocortical responsiveness could delay these processes and result in fetuses which are poorly developed at birth. Reduced HPA axis activity could also have effects for development of the fetal cardiovascular system. Cortisol is thought to be involved in cardiovascular regulation, and infusion of cortisol results in elevation of arterial blood pressure (Tangalakis et al. 1992). In addition, studies in the rat (Langley \& Jackson 1994) and our own experiments in sheep (Hawkins et al. 1997b), have shown that maternal undernutrition alters cardiovascular development of the offspring, producing hypertension in postnatal life. In companion studies, we have shown that maternal undernutrition results in hypotension in the fetus in late gestation (Hawkins et al. 1999). Thus, the reduction of fetal HPA axis activity, which has been demonstrated in the present study, may mediate some of the 'programming' actions of maternal undernutrition on cardiovascular development.

It has been shown that the postnatal hypertension induced by maternal nutritional restriction in the rat is prevented when maternal glucocorticoid synthesis is blocked pharmacologically (Langley-Evans 1997). Thus, the cardiovascular effects of maternal undernutrition may be produced by exposure of the fetus to high plasma glucocorticoid concentrations of maternal origin. This may involve changes in activity and/or levels of the placental enzyme, $11 \beta$-hydroxysteroid dehydrogenase (11 $\beta$-HSD) type 2 , which converts bioactive glucocorticoid to inactive metabolites (Seckl 1997). Therefore, this may also be a mechanism by which development of the fetal HPA axis was altered following maternal undernutrition in the present study.

In conclusion, these studies show that maternal undernutrition can act as a 'programming' factor to produce a reduction in responsiveness of the fetal HPA axis. These effects are even more striking in view of the finding that fetal body weight, body proportions, and blood gas status were not affected by the nutritional challenge. The changes in HPA axis activity may have implications for fetal organ maturation during the final weeks of pregnancy, and for the organism's long term ability to preserve a stable internal environment during postnatal life. Differences in HPA responses to superimposed stress may also have a role in determining the vulnerability to pathology in a number of systems (see McEwen \& Steller 1993). In addition, there is evidence to suggest that the reduction of fetal HPA axis activity may underlie changes in fetal cardiovascular development. In light of recent epidemiological studies linking early life events with altered incidence of adult disease (Barker 1998) and the possible involvement of the HPA axis (Reynolds et al. 1998), it will be particularly important to investigate the mechanisms which produce these effects on the fetal HPA axis, and the implications for development after birth and through to adulthood.

\section{Acknowledgements}

This work was funded by The Wellcome Trust and Medical Research Council. The authors would like to thank Tony Jones and colleagues at the Royal Veterinary College for co-ordinating and performing the dietary manipulations.

\section{References}

AFRC 1993 Energy and protein requirements of ruminants. An advisory manual prepared by the AFRC Technical Committee on Responses to Nutrients. Wallingford, UK: CAB International.

Akagi K \& Challis JRG 1989 Threshold of hormonal and biophysical responses to acute hypoxemia in fetal sheep at different gestational ages. Canadian Journal of Physiology and Pharmacology 68 549-555.

Barker DJP 1998 Mothers, Babies, and Health in Later Life, edn 2. Edinburgh: Churchill Livingstone.

Boddy K, Jones CT, Mantell C, Ratcliffe JG \& Robinson JS 1974 Changes in plasma ACTH and corticosteroid of the maternal and fetal sheep during hypoxia. Endocrinology 94 588-591.

Boshier DP \& Holloway H 1989 Morphometric analyses of adrenal gland growth in fetal and neonatal sheep. I. The adrenal cortex. Journal of Anatomy 167 1-14.

Boshier DP, Holloway H \& Liggins GC 1980 Growth and cytodifferentiation of the fetal lamb adrenal cortex prior to parturition. Journal of Anatomy 130 97-111.

Brooks AN \& White A 1990 Activation of pituitary-adrenal function in fetal sheep by corticotrophin-releasing factor and arginine vasopressin. Journal of Endocrinology 124 27-35.

Clark PM, Hindmarsh PC, Shiell AW, Law CM, Honour JW \& Barker DJP 1996 Size at birth and adrenocortical function in childhood. Clinical Endocrinology 45 721-726.

Crowe C, Bennet L \& Hanson MA 1995 Blood pressure and cardiovascular reflex development in fetal sheep. Relation to hypoxemia, weight, and blood glucose. Reproduction, Fertility and Development 7 553-558.

Fowden AL 1995 Endocrine regulation of fetal growth. Reproduction, Fertility and Development 7 351-363.

Giussani DA, McGarrigle HHG, Moore PJ, Bennet L, Spencer JAD \& Hanson MA 1994 Carotid sinus nerve section and the increase in plasma cortisol during acute hypoxia in fetal sheep. Journal of Physiology 477 75-80.

Glickman JA \& Challis JRG 1980 The changing response pattern of sheep fetal adrenal cells throughout the course of gestation. Endocrinology 106 1371-1376.

Harvey LM, Gilbert RD, Longo LD \& Ducsay CA 1993 Changes in ovine fetal adrenocortical responsiveness after long-term hypoxemia. American Journal of Physiology 264 E741-E747.

Hawkins P, Crowe C, McGarrigle HHG, Saito T, Ozaki T, Stratford LL, Noakes DE \& Hanson MA 1997a Effect of maternal nutrient 
restriction in early gestation on development of the hypothalamicpituitary-adrenal axis in late gestation fetal sheep. Journal of Endocrinology 155 (Suppl) OC4 (Abstract).

Hawkins P, Crowe C, Calder NA, Saito T, Ozaki T, Stratford LL, Noakes DE \& Hanson MA 1997b Cardiovascular development in late gestation fetal sheep and young lambs following modest maternal nutrient restriction in early gestation. Journal of Physiology $50518 \mathrm{P}$ (Abstract).

Hawkins P, Steyn C, Noakes D \& Hanson MA 1999 Effect of maternal nutrient restriction during early gestation on fetal sheep cardiovascular development in late gestation. Early Human Development (Abstract) (In Press).

Iwamoto HS, Rudolph AM, Keil LC \& Heymann MA 1979 Hemodynamic responses of the sheep fetus to vasopressin infusion. Circulation Research 44 430-436.

Jeffray TM, Matthews SG, Hammond GL \& Challis JRG 1998 Divergent changes in plasma ACTH and pituitary POMC mRNA after cortisol administration to late-gestation ovine fetus. American Journal of Physiology 274 E417-E425.

Langley SC \& Jackson AA 1994 Increased systolic blood pressure in adult rats induced by fetal exposure to maternal low protein diets. Clinical Science 86 217-222.

Langley-Evans SC 1997 Hypertension induced by foetal exposure to a maternal low-protein diet in the rat is prevented by pharmacological blockade of maternal glucocorticoid synthesis. Journal of Hypertension 15 537-544.

Liggins GC 1994 The role of cortisol in preparing the fetus for birth. Reproduction, Fertility and Development 6 141-150.

Lu F, Yang K \& Challis JRG 1994 Regulation of ovine fetal pituitary function by corticotrophin-releasing hormone, arginine vasopressin and cortisol in vitro. Journal of Endocrinology 143 199-208.

Lye SJ, Sprague CL, Mitchell BF \& Challis JRG 1983 Activation of ovine fetal adrenal function by pulsatile or continuous administration of adrenocorticotropin(1-24). I. Effects on fetal plasma corticosteroids. Endocrinology 113 770-776.

McEwen BS \& Steller E 1993 Stress and the individual: mechanisms leading to disease. Archives of Internal Medicine 153 2093-2101.

Matthews JNS, Altman DG, Campbell MJ \& Royston P 1990 Analysis of serial measurements in medical research. British Medical Journal 300 230-235.

Norman LJ \& Challis JRG 1987 Synergism between systemic corticotropin-releasing factor and arginine vasopressin on adrenocorticotropin release in vivo varies as a function of gestational age in the ovine fetus. Endocrinology 120 1052-1058.

Phillips DIW, Barker DJP, Fall CHD, Seckl JR, Whorwood CB, Wood PJ \& Walker BR 1998 Elevated plasma cortisol concentrations: a link between low birth weight and the insulin resistance syndrome. Journal of Clinical Endocrinology and Metabolism $83757-760$.

Phillips ID, Simonetta G, Owens JA, Robinson JS, Clarke IJ \& McMillen IC 1996 Placental restriction alters the functional development of the pituitary-adrenal axis in the sheep fetus in late gestation. Pediatric Research 40 861-866.

Reynolds RM, Bendall HE, Walker BR, Wood PJ, Phillips DIW \& Whorwood CB 1998 Hyper-activity of the hypothalamic-pituitaryadrenal axis may mediate the link between impaired fetal growth and the insulin resistance syndrome. Journal of Endocrinology 159 (Suppl) OC5.

Rose JC, MacDonald AA, Heyman MA \& Rudolph AM 1978 Developmental aspects of the pituitary-adrenal axis response to hemorrhagic stress in lamb fetuses in utero. Journal of Clinical Investigation 61 424-434.

Rose JC, Meis PJ \& Morris M 1981 Ontogeny of endocrine (ACTH, vasopressin, cortisol) responses to hypotension in lamb fetuses. American Journal of Physiology 240 E656-E661.

Rose JC, Meis PJ, Urban RB \& Greiss FC 1982 In vivo evidence for increased adrenal sensitivity to adrenocorticotropin(1-24) in the lamb fetus in late gestation. Endocrinology 111 80-85.

Russel A 1991 Body condition scoring of sheep. In Sheep and Goat Practice, pp 3-10. Ed E Boden. Baillière Tindall.

Seckl JR 1997 Glucocorticoids, feto-placental 11 $\beta$-hydroxysteroid dehydrogenase type 2 , and the early life origins of adult disease. Steroids 62 89-94.

Tangalakis K, Coghlan JP, Connell J, Crawford R, Darling P, Hammond VE, Haralambidis J, Penschow J \& Wintour EM 1989 Tissue distribution and levels of gene expression of three steroid hydroxylases in ovine fetal adrenal glands. Acta Endocrinologica 120 225-232.

Tangalakis K, Lumbers ER, Moritz KM, Towstoless MK \& Wintour EM 1992 Effect of cortisol on blood pressure and vascular reactivity in the ovine fetus. Experimental Physiology 77 709-717.

Wintour EM, Brown EH, Denton DA, Hardy KJ, McDougal JG, Oddie CJ \& Whipp GT 1975 The ontogeny and regulation of corticosteroid secretion by the ovine fetal adrenal. Acta Endocrinologica 79 301-316.

Received 1 June 1998

Revised manuscript received 2 November 1998

Final version received 20 May 1999

Accepted 13 July 1999 